Linha D'Água (Online), São Paulo, v. 30, n. 2, p. 35-50, out. 2017

\title{
(CON) FABULANDO NA PRAÇA: A CRIAÇÃO DE ESPAÇOS LITERÁRIOS E LÚDICOS NO FESTIVAL DO LIVRO E DA LITERATURA DE SÃO MIGUEL PAULISTA
}

\author{
FABULATING IN THE SQUARE: THE CREATION OF LITERARY \\ AND LUDIC SPACES IN THE FESTIVAL OF THE BOOK AND \\ LITERATURE IN SÃO MIGUEL PAULISTA
}

\author{
Felba Carvalho* \\ Universidade Cruzeiro do Sul, São Paulo, SP, Brasil
}

\begin{abstract}
Resumo: 0 objetivo deste trabalho é apresentar os resultados de uma experiência prática de incentivo à leitura de textos literários em projetos que coordeno, durante quatro anos, com os alunos do Curso de Letras da Universidade Cruzeiro do Sul, para o Festival do Livro e da Literatura de São Miguel Paulista. Todas as atividades propostas no evento buscam resgatar a tradição oral de contar histórias e "a arte de contá-las de novo", conforme Walter Benjamin (1994) e ressignificar o espaço público (a praça), onde ocorre o Festival, transformando-o em um espaço lúdico com intervenções literárias e artísticas que promovam transformações ou reações, sejam elas intelectuais, sensoriais ou físicas no público, em sua maioria, alunos de escolas públicas e privadas da Zona Leste. Neste sentido, o futuro professor, aluno do Curso de Licenciatura em Letras, tem a oportunidade de se relacionar com jovens e crianças, durante três dias ininterruptos, em um espaço fora do ambiente escolar, criando situações de interação que exijam dele conhecimento sobre a literatura, gosto pela leitura, criatividade, capacidade de trabalhar em equipe e interagir com o público e, sobretudo, de responsabilidade social nas ações propostas, a fim de sensibilizar o público participante por meio da literatura.
\end{abstract}

Palavras-chave: Festival do Livro e da Literatura; incentivo à leitura literária; espaços lúdicos.

\begin{abstract}
The aim of this work is to show the results of a practical experience of motivation to reading literature texts in projects I have coordinated for four years with the students of the Literature course from Universidade Cruzeiro do Sul, in the Festival of the Book and Literature in São Miguel Paulista. All the proposed activities in the event aim at recovering the oral tradition of storytelling and "the art of re-telling them over and over again", according to Walter Benjamin (1994) and re-signifying them in the public space (the square) where the Festival takes place, transforming it in a ludic space with literary and artistic interventions that could promote transformations or reactions which may have an intelectual, sensorial or physical impact in the audience, comprised mostly of students from public and private schools in the East side of São Paulo. In this sense, the future teacher, who is also a student from the Literature course, has the opportunity to relate to youngsters and children for three days in a different space from the school environment, creating situations of interaction that demand their knowledge about literature, a taste for literature, creativity, teamwork and interaction to the public and, above all, social responsibility associated to the proposed activities, aiming at raising awareness of the audience by means of literature.
\end{abstract}

Keywords: Festival of the Book and Literature; Incentive to Literary Reading; Ludic Spaces.

* Professora doutora da Universidade Cruzeiro do Sul - UNICSUL, São Paulo, SP, Brasil; augustomatraga@yahoo.com 
Linha D'Água (Online), São Paulo, v. 30, n. 2, p. 35-50, out. 2017

\section{Introdução: na praça, onde fudo começou}

Organizado desde 2006 pela Fundação Tide Setúbal, o Festival do Livro e da Literatura de São Miguel Paulista começou como Feira do Livro no Clube da Comunidade Tide Setubal, cujo objetivo principal é democratizar a leitura e o acesso à literatura. Com o passar dos anos, a Fundação ampliou as parcerias e se tornou um evento coletivo, ocupando diferentes espaços da Zona Leste, em São Miguel Paulista. Em 2016, foram quase 50 pontos de São Miguel Paulista, envolvendo a participação de instituições culturais, escolas públicas e privadas, coletivos, universidades, com diferentes ações capazes de aproximar o público dos livros. A criação do evento na região foi motivada, também, por ter um dos piores índices de livros disponíveis para o público adulto da cidade de São Paulo: 0,44 por habitante, na faixa etária acima de 15 anos, quando o recomendado pela Unesco fica em, no mínimo, dois por habitante.

Em 2012, nos dias 8 e 9 de novembro, os alunos do Curso de Letras foram convidados pela equipe organizadora do Festival do Livro a participar do "Sarau: Liberte a Poesia!" (evento que ocorreu dentro do Festival) organizado pelo SESC Itaquera, declamar poemas de Manuel Bandeira, Vinícius de Moraes e Carlos Drummond de Andrade e, como ouvintes, assistiram às mesas-redondas com escritores, como Pedro Bandeira, e em uma conversa com o poeta Ferreira Gullar, realizada no último dia do Festival, na Praça Fortunato da Silveira, conhecida localmente como Praça Morumbizinho, localizada em frente à Universidade Cruzeiro do Sul, em São Miguel Paulista. O contato com o poeta em uma grande tenda montada na praça ao lado da universidade provocou, nos alunos e em mim, como professora de literatura, as seguintes problematizações naquele ano: por que não tínhamos conhecimento deste evento antes? Será que estávamos tão alienados em nossa sala de aula que não conseguimos enxergar o que está sendo feito fora dela? Se Ferreira Gullar veio do Rio de Janeiro para São Miguel Paulista conversar com jovens e crianças da região sobre literatura e incentivá-los à leitura, por que não estamos fazendo o mesmo enquanto Curso de Licenciatura em Letras que formará futuros professores?

A partir desses questionamentos, finalizado o Festival do Livro e da Literatura de São Miguel Paulista, conversamos com Inácio Pereira dos Santos Neto, 
Linha D'Água (Online), São Paulo, v. 30, n. 2, p. 35-50, out. 2017

coordenador do Núcleo ArteCulturAção, da Fundação Tide Setubal, e organizador do evento, e firmamos nossa parceira para o próximo Festival, que ocorreu em novembro de 2013. Ao longo do primeiro semestre daquele ano, em reuniões com os alunos do Curso, pensamos em como poderíamos utilizar o que tínhamos visto em nossas aulas de Teoria da Literatura e Literatura Brasileira, que poderia refletir em nossos projetos para o evento, ou seja, quais vozes teóricas, literárias poderiam nos guiar na forma como abordaríamos a literatura fora da sala de aula, atendendo à comunidade em espaços públicos, como uma praça. O primeiro teórico citado foi Walter Benjamin. Nas aulas de Teoria da Literatura: Prosa, havia discutido com os alunos sobre a estrutura da narrativa e o papel do narrador, sobre sua experiência passada de pessoa para pessoa, das histórias orais contadas por narradores anônimos, seja o camponês sedentário ou o marinheiro comerciante, nos exemplos de Walter Benjamin (1994, p. 205):

Contar histórias sempre foi a arte de contá-las de novo, e ela se perde quando as histórias não são mais conservadas. Ela se perde porque ninguém mais fia ou tece enquanto ouve a história. Quanto mais o ouvinte se esquece de si mesmo, mais profundamente se grava nele o que é ouvido. Quando o ritmo do trabalho se apodera dele, ele escuta as histórias de tal maneira que adquire espontaneamente o dom de narrá-las. Assim se teceu a rede em que está guardado o dom narrativo. E assim essa rede se desfaz hoje por todos os lados, depois de ter sido tecida, há milênios, em torno das mais antigas formas de trabalho manual.

Com estas palavras de Walter Benjamin, pensamos em como poderíamos tornar as histórias mais vivas e mais próximas dos ouvintes, das crianças e jovens que vão assistir ao evento. Em todas as atividades que programaríamos, teríamos que ter a preocupação de resgatar essa tradição de trazer as histórias originais, mesmo diante dos apelos midiáticos e de algumas adaptações que se distanciam demasiadamente dos textos primordiais. $\mathrm{O}$ desafio seria contar as histórias como se o narrador tivesse vivenciado as mesmas e, ao mesmo tempo, torná-las útil para os ouvintes:

Tudo isso esclarece a natureza da verdadeira narrativa. Ela tem sempre em si, às vezes de forma latente, uma dimensão utilitária. Essa utilidade pode consistir seja num ensinamento moral, seja numa sugestão prática, seja num provérbio ou

CARVALHO, H. (Con) fabulando na praça: a criação de espaços literários e lúdicos no Festival do Livro 
Linha D'Água (Online), São Paulo, v. 30, n. 2, p. 35-50, out. 2017

numa norma de vida - de qualquer maneira, o narrador é um homem que sabe dar conselhos. Mas, se "dar conselhos" parece hoje algo de antiquado, é porque as experiências estão deixando de ser comunicáveis. (BENJAMIN, 1994, p. 207).

Como boa parte das atividades realizadas pelos alunos do Curso de Letras estão relacionadas às performances teatrais e de contação de histórias, conforme será visto mais adiante neste artigo, o desafio não seria apenas recuperar a narrativa e sua origem na tradição oral da poesia épica, conforme observou Benjamin, mas que se a narrativa oral morre com o advento do romance e do livro, em uma perspectiva pessimista do autor sobre a escrita isolada e individualizada desse gênero, o livro continua assumindo a cota de ficção que precisamos ter nas nossas 24 horas do dia, conforme ensinou Candido:

Alterando um conceito de Otto Ranke sobre o mito, podemos dizer que a literatura é o sonho acordado das civilizações. Portanto, assim como não é possível haver equilíbrio psíquico sem o sonho durante o sono, talvez não haja equilíbrio social sem a literatura. Deste modo, ela é fator indispensável de humanização e, sendo assim, confirma o homem na sua humanidade, inclusive porque atua em grande parte no subconsciente e no inconsciente. Neste sentido, ela pode ter importância equivalente à das formas conscientes de inculcamento intencional, como a educação familiar, grupal ou escolar. Cada sociedade cria as suas manifestações ficcionais, poéticas e dramáticas de acordo com os seus impulsos, as suas crenças, os seus sentimentos, as suas normas, a fim de fortalecer em cada um a presença e atuação deles. (1995, p. 177)

Assim, também lembramos dos ensinamentos de Antonio Candido, do texto "O Direito à Literatura", primeiro a ser discutido com os alunos nas aulas iniciais de Teoria da Literatura. A definição ampla de literatura do crítico literário que abarca desde o folclore, a lenda até as formas mais complexas escritas das grandes civilizações (1995, p. 176), parecia adequada para os diferentes projetos que poderíam ser realizados no evento, conforme será visto a seguir. Dessa forma, partindo do pressuposto que as formas mais complexas de literatura também incorporam outros gêneros mais simples, como o próprio folclore e a lenda, se pensarmos nos livros de Monteiro Lobato até Macunaíma, de Mário de Andrade, temos a

CARVALHO, H. (Con) fabulando na praça: a criação de espaços literários e lúdicos no Festival do Livro 
Linha D'Água (Online), São Paulo, v. 30, n. 2, p. 35-50, out. 2017

possibilidade de apresentar o universo de fabulação em diferentes níveis e o seu sentido humanizador como

\begin{abstract}
... um processo que confirma no homem aqueles traços que reputamos essenciais, como o exercício da reflexão, a aquisição do saber, a boa disposição para com o próximo, o afinamento das emoções, a capacidade de penetrar nos problemas da vida, o senso da beleza, a percepção da complexidade do mundo e dos seres, o cultivo do humor. A literatura desenvolve em nós a quota de humanidade na medida em que nos torna mais compreensivos e abertos para a natureza, a sociedade, o semelhante. (1995, p. 177)
\end{abstract}

Além de recuperar sua tradição oral, de trazer um ensinamento moral e de humanizar, a literatura deveria, também, ensinar a pensar, outro aspecto que incluímos em nossos objetivos a serem contemplados nos projetos para o Festival do Livro. Neste sentido, lembrei com os alunos das minhas aulas de literatura infanto-juvenil com a professora Nelly Novaes Coelho, nos anos 90, na Faculdade de Letras da USP. A pesquisadora traz um ponto relevante de problematização sobre questões estéticas e pedagógicas na década de 60. Coelho (1966, p. 17-18) recomenda que, nas séries iniciais, o objetivo principal deveria ser despertar o entusiasmo pela leitura, despertando nas crianças a capacidade de observação, fazendo-as aprender a pensar, para formar a escala de valores que vai dirigir os seus atos na vida adulta. Dessa forma, é de grande importância saber que tipo de livro selecionar, o que vai ser transmitido aos pequenos leitores, uma vez que eles aceitam com facilidade histórias fantásticas, cheias de fantasia, como contos, fábulas etc. Como educadores, precisamos estar atentos quanto aos valores que os alunos estarão recebendo nestas leituras, e, mesmo enquanto narradores das histórias para as crianças, "damos conselhos", lembrando a experiência do narrador de Walter Benjamin.

Segundo Zilberman (2003, p. 176), "a literatura deve se integrar ao projeto desafiador próprio de todo fenômeno artístico, impulsionar ao seu leitor uma postura crítica, inquiridora, e dar margem à efetivação dos propósitos da leitura como habilidade humana." Mesmo quando contamos a história de um conto de fadas, estimulamos

CARVALHO, H. (Con) fabulando na praça: a criação de espaços literários e lúdicos no Festival do Livro 
Linha D'Água (Online), São Paulo, v. 30, n. 2, p. 35-50, out. 2017

a criatividade, a imaginação, a brincadeira, a leitura, a escrita, a música, o querer ouvir novamente, desenvolvendo dessa forma a oralidade nas crianças dessa faixa etária, considerado como um importante e significativo veículo de comunicação entre elas. (COELHO, 2003, p. 21).

Assim, pensando nesses conceitos e no público variado de crianças e jovens, desde a educação infantil ao ensino médio, que passamos a desenvolver os projetos para os Festivais do Livro e da Literatura, conforme será visto a seguir.

\section{O primeiro Festival do Livro: Machado de Assis dá as cartas}

Em agosto de 2013, começamos os nossos primeiros diálogos com Inácio Pereira dos Santos Neto, organizador do Festival do Livro e da Literatura de São Miguel Paulista. O evento aconteceu nos dias 7, 8 e 9 de novembro. Destacaram-se, em 2013, a adesão de mais de 50 instituições de ensino, ONGs e coletivos culturais, a doação de 4.900 livros, as vendas de centenas de títulos com descontos, por dez editoras, e as conversas com os escritores Ignácio de Loyola Brandão, Fabrício Carpinejar, Paulo Lins, Ferréz e Leonardo Sakamoto, além das presenças do comunicador social colombiano Jorge Melguizo, criador dos primeiros parques-biblioteca da cidade de Medellín, e do secretário municipal da Cultura de São Paulo, Juca Ferreira.

Para todas as atividades que organizamos para os quatro Festivais, adotamos a seguinte dinâmica:

1) Os alunos do curso iniciam a elaboração de projetos para o evento nos meses de julho e agosto; em setembro, elaboram a programação de atividades, que é enviada para o organizador do evento, Inácio Neto;

2) Depois, são organizadas as oficinas de produção de materiais para os cenários das tendas e ensaios para as apresentações;

3) Uma semana antes do evento, os monitores (alunos do curso) são divididos de acordo com o número de tendas e outros são orientados a fazer a recepção das escolas e dos demais visitantes;

4) Nos dias do evento, com o apoio da Coordenação do Curso de Letras e da Pró -Reitoria de Extensão e Assuntos Comunitários da Universidade Cruzeiro 
do Sul, todos os alunos do Curso de Letras são dispensados das aulas para se dedicarem, integralmente, às atividades do Festival.

Também, nos três meses que antecedem o evento, os alunos iniciam uma campanha de doação de livros entre os professores e alunos do curso e dos outros cursos da universidade. Os livros arrecadados são entregues à Fundação Tide Setúbal, que distribui os exemplares nas árvores durante os três dias do evento.

Nas quatro reuniões que tivemos, em 2013, com o organizador do Festival, trocamos algumas ideias e propusemos quatro projetos para o evento. Sem verba da Universidade e da Fundação Tide Setúbal, que passo a chamar de agora em diante pela sigla FTS, tivemos que pensar em propostas que utilizassem o mínimo de recursos financeiros, que depois foram divididos entre mim e a coordenação do Curso de Letras. As tendas montadas na praça, nos dias do Festival, foram cedidas pela FTS, onde criamos os espaços lúdicos para colocar em prática os projetos. Como o tema dessa edição do Festival foi livre, escolhemos um cânone da literatura brasileira, Machado de Assis, cuja voz, seja por meio de seus narradores ou de suas personagens, esteve presente em todos os quatro projetos, que passo a descrevê-los:

1) "Caminhos lúdicos, paradas fabulares". Com vestidos de época ou caracterizados como as personagens dos romances, alunos do Curso de Letras interpretaram diferentes personagens da literatura como Capitu, Brás Cubas, Madame Bovary, Macabéa, Gabriela, Iracema, Macunaíma. As personagens percorreram as alamedas da Praça Fortunato da Silveira, apresentando-se para o público, contando suas histórias, utilizando a própria praça, com suas árvores e alamedas, como cenário para suas histórias. A surpresa dessa ação foi a presença de Machado de Assis, interpretada por um aluno, que interferia na fala de suas personagens propondo questionamentos e reflexões sobre sua própria produção. No meio da caminhada, acompanhando cada personagem, os visitantes encontravam momentos de parada, a fim de interagirem com personagens famosos, entrando em seus universos fabulares, fazendo parte de suas histórias;

2) Estação "Mais médicos": os doutores na literatura". Em diálogo com o Programa "Mais Médicos", do Ministério da Saúde, em uma tenda foi montada 
Linha D'Água (Online), São Paulo, v. 30, n. 2, p. 35-50, out. 2017

uma estação médica, que trazia um primeiro atendimento realizado por alunas vestidas de enfermeiras que faziam uma triagem a partir de um questionário identificando quais os problemas do paciente, relacionados aos órgãos: rins, coração, estômago, fígado, pulmão, sistema nervoso, visão, audição etc. Após a triagem, os pacientes eram encaminhados para os "médicos" Dr. Jekyll, de O médico e o monstro, de Robert Louis Stevenson, e Dr. Simão Bacamarte, de O alienista, de Machado de Assis. Os "pacientes" eram medicados com "pílulas literárias" (cápsulas contendo um pequeno papel com trechos de contos, romances ou poemas que pudessem se relacionar simbolicamente com cada órgão, mas principalmente com o pior dos males, a falta de leitura);

3) "A Cartomante". Nesta tenda, o visitante encontrava um misto de duas personagens literárias, a cartomante do conto de Machado de Assis e de $A$ Hora da Estrela, de Clarice Lispector. Essa personagem, representada por alunas do Curso de Letras, jogava as cartas de tarot, interpretando os desenhos a partir de trechos de textos literários colados no verso das cartas, fazendo refletir sobre a capacidade que a literatura tem de sugerir caminhos e reflexões acerca da vida. Filas se formaram para consultar a cartomante que, em muitos casos, passou a ser confundida com uma verdadeira cartomante;

4) "Sarau sobre rodas". Um carro com megafone fez um circuito em ruas no entorno da Universidade Cruzeiro do Sul anunciando o Festival do Livro e da Literatura de São Miguel Paulista. O carro fazia paradas programadas para pequenos saraus, realizados por alunos do Curso de Letras, sobre trechos de livros que foram distribuídos para os espectadores, a partir do Programa "De mão em mão". Os livros foram doados pela FTS e entregues aos alunos do Curso que fizeram a entrega de 1.100 exemplares. Os títulos dos livros são os seguintes: Missa do Galo e outros contos, de Machado de Assis; A nova Califórnia e outros contos, de Lima Barreto; São Paulo! comoção de minha vida..., de Mário de Andrade; Contos paulistanos, de Antônio de Alcântara Machado; Histórias de horror. Vários autores.

As quatro atividades propostas pelos alunos do Curso de Letras atenderam uma média de 600 alunos da rede pública e privada, além do público espontâneo 
Linha D'Água (Online), São Paulo, v. 30, n. 2, p. 35-50, out. 2017

que circulou pela praça. Mais de 100 alunos do Curso de Letras participaram do evento, atuando nos projetos ora como personagens, ora como monitores que conduziam o público às tendas e orientavam sobre a programação do Curso e das demais atividades propostas por outras instituições. Nesse sentido, as ações propostas buscaram aproximar a literatura ao cotidiano das pessoas, colocando-as em contato com algumas personagens importantes da literatura canônica. Nesta primeira participação do Curso no evento, sentimos a necessidade de criar mais projetos voltados para as crianças da Educação Infantil, além de propor o diálogo da literatura com outras artes. Assim, pensamos nas propostas para 2014.

\section{Dos Contos de fadas às histórias do Sítio do Pica-Pau Amarelo}

Com o reconhecimento elogioso das atividades realizadas pelo Curso no ano anterior, por parte da FTS e por Maria Alice Setúbal, passamos a ter o financiamento do aluguel das fantasias nos projetos realizados para a edição do Festival de 2014. Neste ano, propusemos projetos que atendessem mais ao público infantil. Assim, mergulhamos no universo das fábulas e contos de fadas, despertando a imaginação dos pequenos com as contações de histórias dos alunos em cinco atividades organizadas em quatro tendas:

1) "Contos, cantos e brincadeiras no Sítio do Pica-Pau Amarelo". Em uma tenda, com motivos das histórias de Monteiro Lobato, os personagens do Sitio do Pica Pau Amarelo descobrem que estão fora dos livros e passam a interagir com o público através da contação de histórias, brincadeiras e músicas. Os personagens também lembram a importância de se preservar um livro. A visita da Mãe Natureza durante o espetáculo trouxe uma lição a todos sobre o amor e respeito que devemos ter para com o Ser Humano e o Meio Ambiente;

2) “Contações de Histórias, Arte e Cultura: intervenções com origami”. Em uma tenda, com motivos orientais, foram contadas histórias da tradição oriental com a arte em origami, entre outras. Além de valorizar a importância do hábito de ouvir e o prazer de ler, buscamos com essa intervenção cultural levar o incentivo à leitura e, com ela, conhecimentos sobre a arte e a literatura orientais; 
Linha D'Água (Online), São Paulo, v. 30, n. 2, p. 35-50, out. 2017

3) "Fabulando no bosque: encontro com as personagens dos contos de fadas". A atividade foi desenvolvida a partir de espaços lúdicos na Praça Morumbizinho e em uma tenda central, onde diferentes personagens dos contos de fada, como Chapeuzinho Vermelho, "Chapeuzinho Amarelo", Lobo Mau, Caçador, Cinderela, Branca de Neve, Bela Adormecida, Rapunzel, Bruxa da Branca de Neve, Madrasta da Cinderela, Malévola, Mago Lerlin, entre outros, e personagens do Sítio do Pica-Pau Amarelo unem suas histórias e interagirem com o público em várias situações e espaços inusitados, como a Cabana dos irmãos Grimm e a Toca do Dragão;

4) "Baile da Cinderela". Trata-se do momento final da atividade "Fabulando no bosque”. Todas as personagens se reúnem na arena da praça e bailam com o público. É quase no final do baile que a Cinderela perde seu sapatinho de cristal e o público sai pelo bosque, para procurá-lo. Aquele que encontrou o sapato, ganhou um quite de livros de contos de fadas;

5) “Contos de Fadas Esquecidos”. A proposta da atividade foi resgatar o universo dos contos de fadas dos Irmãos Grimm. O evento começou com a Festa do Chá, com Alice, a Rainha de Copas e outros personagens em volta da mesa para contar algumas histórias, como: O Gato de Botas, A Pequena Vendedora de Fósforos, O Pequeno Polegar, entre outras. Após a Festa do Chá, os personagens se reuniram em volta de uma fogueira para contar as versões originais de suas histórias, como João e Maria, Cinderela, Branca de Neve e outros. A ideia foi mostrar que todas as versões dessas histórias conhecidas pelo público tem um lado oculto e misterioso.

Neste ano, tivemos também a participação de mais de 100 alunos do Curso de Letras e mais de 1.000 visitantes que participaram das atividades propostas, entre crianças, jovens e adultos. Com o apoio e organização da Fundação Tide Setubal, os projetos ganharam visibilidade e, pelo segundo ano, a Rede Globo dedicou um bloco inteiro do SPTV, $1^{\mathrm{a}}$ edição, às atividades dos licenciandos, entre as outras do evento.

CARVALHO, H. (Con) fabulando na praça: a criação de espaços literários e lúdicos no Festival do Livro 
Linha D'Água (Online), São Paulo, v. 30, n. 2, p. 35-50, out. 2017

\section{As diferentes vozes para construir histórias: contos, lendas e cordel}

O tema "Diferentes Vozes para Construir Histórias" celebrou a essência do Festival do Livro e da Literatura de São Miguel Paulista em sua edição de 2015. Nesta sexta edição, quando a democracia brasileira completou 30 anos, a proposta foi debater com diferentes escritores de que forma ela vem sendo construída e como a história real, a ficção, as redes sociais se cruzam para garantir direitos e contribuir com a cidadania.

A partir dessa temática, além dos contos infantis que tiveram uma grande receptividade por parte do público no ano anterior, procuramos nas narrativas populares, nas lendas e no folclore, organizar sete atividades em três tendas:

1) “Amigos da cobra: Celeste conta histórias fora do Castelo". Em uma tenda, montada em frente a uma grande árvore da praça Morumbizinho, a Cobra Celeste e mais alguns personagens do Castelo Rá-Tim-Bum, interpretados por alunos do Curso de Letras despertaram a imaginação de crianças, jovens e adultos com histórias africanas e indígenas, como: "Os Gêmeos do Tambor" e "Erilé, o caçador", além de promoverem brincadeiras a partir da lenda do folclore amazônico "Cobra Grande". No final de cada apresentação, as crianças foram convidadas a brincar e a cantar a música Aram Sam Sam, de origem marroquina;

2) “O livro de histórias da Wendy”. Personagens clássicos da literatura infantil como a Rainha da Neve, Alladin e Jasmin, Bela, Alice, Rainha de Copas, Grilo Falante, Wendy, Peter Pan, Sininho e Capitão Gancho convidaram o público a interagir com a encenação da peça "O livro de Histórias da Wendy". Tratou-se de uma tenda cenográfica, montada como o quarto dos irmãos Wendy, Pedro e Miguel. No enredo, as crianças resolveram ler histórias para dormir. Peter Pan aparece e toda magia começa. As histórias contadas viram realidade e as personagens surgem para assumir seus papéis, transformando o quarto em um mundo de imaginação, criando um espaço lúdico de incentivo à leitura, propondo um resgate dos contos de fada em sua forma mais literária, através de seus símbolos;

CARVALHO, H. (Con) fabulando na praça: a criação de espaços literários e lúdicos no Festival do Livro 
Linha D'Água (Online), São Paulo, v. 30, n. 2, p. 35-50, out. 2017

3) Na tenda "Caminhos para o Cordel", decorada com artigos do nosso sertão, foram realizadas seis atividades: a primeira, intitulada "Lampião, Maria Bonita e seus cangaceiros", os alunos do curso, vestidos de Lampião, Maria Bonita e cangaceiros, abriram os dois períodos do Festival, manhã e tarde, com música regional, trazendo a literatura e a música tão marcante do povo nordestino; na segunda atividade, "Cortejo Mulher rendeira", um chamado sonoro alertava que era momento do cortejo passar! Ao som de "Mulher Rendeira”, Lampião, com seu acordão, levou o cortejo, seguido da mulher rendeira, dos cangaceiros, João Grilo e Chicó, todos cantando e dançando, formando um cordão na praça, convidando crianças, jovens e adultos a participarem; a terceira atividade, "Oficina de Isogravura", convidou as crianças a produzir desenhos a partir dos motivos nordestinos e das histórias de cordel, utilizando técnicas em isogravura, orientadas por monitores do Curso de Letras da Universidade Cruzeiro do Sul. Ao final, as crianças assinaram suas criações que foram afixadas na tenda, para apreciação do público. Na quarta atividade, denominada "Encandeados", a vida, a alegria e a arte do sertão e do retirante foram ilustradas nesta atração em estruturas de guarda-chuvas que formaram espaços lúdicos individuais. $\mathrm{O}$ público foi convidado a refletir e a se retirar, simbolicamente, para romances consagrados, como: Os Sertões, Morte e Vida Severina, Vidas Secas, Grande Sertão: Veredas, O Quinze e a Hora da Estrela. Cangaceiros circularam pela praça capturando crianças, adolescentes e adultos para encadeá-los nesse espaço lúdico. Os convidados ou seus amigos foram convidados a improvisar versos ou cantar uma cantiga de roda para libertarem os encandeados. A última atividade, "Baile Rei do Baião", configurou-se como um baile de encerramento das atividades realizadas nesta tenda, onde, ao som do Rei do Baião, todos os participantes e monitores de todas as tendas convidaram o público para dançarem forró e a se juntarem nesta grande festa.

\section{A voz feminina na literatura}

Com o tema Narrativas de gênero: feminino, feminismo e outras histórias, o Festival do Livro e da Literatura de São Miguel Paulista chegou a sua 7a edição. O 
Linha D'Água (Online), São Paulo, v. 30, n. 2, p. 35-50, out. 2017

encontro aconteceu nos dias 09, 10 e 11 de novembro de 2016, em São Miguel Paulista, em mais de 40 pontos da região. Como acontece anualmente, a programação foi elaborada por escolas, coletivos, instituições locais que juntas refletiram sobre o tema. Os alunos do Curso de Letras, como no ano passado, elaboraram uma programação diversificada que atendesse o público infanto-juvenil e os adultos. Foram cinco projetos que resultaram em cinco tendas na Praça Morumbizinho, o maior número de espaços lúdicos que tivemos nos quatro anos de evento. Com a preocupação de trazer a voz feminina na literatura, desde os clássicos até best-sellers, como Harry Potter, os projetos deram destaque para a literatura estrangeira, conforme se observa a seguir:

1) “Convenção das Bruxas”. Do que será que as bruxas falam quando se encontram? É o que Glinda, a Bruxa Boa do Sul e Elphaba, a Bruxa Má do Oeste mostraram para as crianças junto de suas amigas e amigos: Mágico de $\mathrm{Oz}$, Mago Merlin, Morgana e muitos outros. Nesta encenação, as bruxas se encontraram para uma convenção anual, na casa da bruxa Elphaba, para discutirem sobre seus papéis nas lendas e contos infantis, explorando um ponto de vista desconhecido pelas crianças. Com leveza e bom humor, as personagens convidaram o público do Festival do Livro e da Literatura a refletirem sobre conceitos internalizados sobre o feminino, quebrando mitos e preconceitos. O projeto trouxe a reflexão sobre a figura feminina de uma forma lúdica, que fez com que as crianças vissem as bruxas dos contos infantis com um olhar totalmente novo;

2) "O feminino no universo mágico de Harry Potter". Nesta tenda, foram realizadas diferentes atividades. Vestindo os personagens de Harry Potter, foram montadas equipes representando as casas de Hogwarts: Grifinória, Sonserina, Corvinal e Lufa-lufa. A dinâmica possibilitou às crianças treinar sua memória visual, a percepção, a coordenação motora, além do trabalho em equipe. Além disso, as equipes escolheram personagens da tenda para ajudá-las a identificar e responder perguntas sobre as personagens de J.K. Rowling. A cada acerto, a equipe ganhou pontos que foram somados à competição geral das casas Grifinória, Sonserina, Corvinal e Lufa-lufa. A 
Linha D'Água (Online), São Paulo, v. 30, n. 2, p. 35-50, out. 2017

atividade possibilitou a criança identificar as vozes femininas dentro dos textos e o que elas representam em nossa sociedade;

3) "A Pequena Princesa e seus amigos: uma adaptação do livro O Pequeno Príncipe." Com personagens inspirados na história infantil O Pequeno Príncipe, de Antoine de Saint- Exupéry, os alunos do Curso de Letras convidaram o público a conhecer a história adaptada de "A Pequena Princesa e seus amigos" e a compreender a importância de uma amizade e da igualdade entre os gêneros;

4) A tenda "Mulher: o sexo frágil? Ah, nem nos livros!" apresentou um confronto entre personagens femininas da literatura fantástica clássica e atual, incentivando o público a refletir sobre a maneira como a mulher é vista nos livros. $\mathrm{O}$ debate se iniciou com a encenação de uma aula em que o professor instiga os alunos a refletirem sobre o conceito atual de feminismo; essa reflexão foi conduzida pelas personagens das histórias fantásticas: Cinderela, Hermione, Aurora, Katniss, Branca de Neve e Daenerys. Em um segundo momento, o professor iniciou uma dinâmica, para fazer com que o público entrasse no debate, de maneira que o foco se voltasse para questões da sociedade atual;

5) “Jogo de tabuleiro". Personagens femininas clássicas, da nossa Literatura Brasileira, foram presas dentro de um tabuleiro de jogos. Com a ajuda do público para libertá-las, a tenda propôs diferentes jogos (cruzadinha, caça palavras, adivinhação, forca, quiz e leitura) de desafios que estavam presentes no tabuleiro, onde cada casa era um desafio a ser cumprido pelo peão. A cada desafio cumprido, uma das personagens era libertada, mas para ela ter a certeza disso, um participante deveria descrevê-la e, com isso, apresentar para todos os presentes dentro da tenda.

As atividades foram encerradas com o Sarau "A Voz da Vez: A representatividade do eu lírico feminino". Os alunos do curso de Letras convidaram todos a participar do sarau lendo poemas cuja voz representada fosse a feminina. Tratou-se de uma intervenção artística que buscou a representatividade do eu lírico feminino na música e na literatura e contou, também, com uma fogueira onde foram queimados símbolos dos paradigmas e preconceitos que existem na sociedade e que afetam as mulheres diretamente. $\mathrm{O}$ objetivo foi fomentar o debate sobre a 
Linha D'Água (Online), São Paulo, v. 30, n. 2, p. 35-50, out. 2017

participação do feminino e a igualdade de gênero, fechando o ciclo temático norteador da participação dos alunos da Unicsul nas atividades do Festival.

Nesta edição conseguimos a doação de 12 exemplares do livro O Pequeno Principe, da Geração Editorial e 15 exemplares de Harry Potter, da Editora Rocco. Os exemplares foram sorteados nos três dias do Festival para o público. Tivemos uma média de 60 alunos voluntários do Curso de Letras atendendo uma média diária de 600 jovens e crianças de escolas públicas e privadas da região, totalizando, aproximadamente, um público de 1.800 pessoas, só nas tendas montadas pelos alunos do Curso de Letras.

\section{Considerações Finais}

Nestes quatro anos de participação no Festival do Livro e da Literatura de São Miguel Paulista, os discentes do Curso de Letras viveram uma experiência prática e lúdica com crianças e jovens de diferentes escolas e níveis, contribuindo para a formação dos futuros docentes, que perceberam, durante o evento, que há outras formas de incentivo à leitura e de falar sobre a literatura. Como professora do curso, observo que muitos alunos se descobrem no Festival e ficam mais convictos da escolha que fizeram: a docência. Para a Universidade, é uma forma de se relacionar com a comunidade, ocupando outros espaços e assumindo sua responsabilidade social. São quatro anos de experiência, com resultados sempre positivos, que podem ser confirmados na fala dos próprios alunos do Curso, que estão construindo parte da história desse evento. Destaco um aluno, em especial, que, por três anos, concretizou os vários projetos apresentados a cada ano, Luiz Felipe Condez, cuja fala comprova esse resultado: "Interagir com as crianças é maravilhoso. A gente sabe quando o olho brilha, quando o sorriso aparece, que o projeto está dando certo" e isso se reproduz nas falas que os alunos colheram ao longo dos anos e que se repete na voz das crianças: "Este é o dia mais feliz da minha vida, porque eu pude sonhar com as histórias contadas aqui, agora quero ler essas histórias". Sabemos, com isso, que a literatura cumpriu o seu papel, de humanizar, de entrega ao universo fabulado.

CARVALHO, H. (Con) fabulando na praça: a criação de espaços literários e lúdicos no Festival do Livro 
Linha D'Água (Online), São Paulo, v. 30, n. 2, p. 35-50, out. 2017

\section{Referências}

BENJAMIN, W. "O narrador: considerações sobre a obra de Nikolai Leskov". Magia e técnica, arte e política: ensaios sobre literatura e história da cultura. São Paulo: Brasiliense, 1994. p. 197-221.

CANDIDO, A. "Direito à Literatura”. In: Vários escritos - edição revista e ampliada. São Paulo: Duas Cidades, 1995.

COELHO, N. N. O ensino da Literatura. São Paulo: FTD, 1966.

Literatura Infantil: Teoria Analise Didática. 6. ed. São Paulo. Moderna, 2003.

FESTIVAL DO LIVRO E DA LITERATURA DE SÃO MIGUEL PAULISTA. Disponível em https://www.youtube.com/watch?v=t9Kqxb6-4cM. Acesso em 02 de junho de 2017, às 15h.

Festival do livro e da literatura de São Miguel - 2014 - SPTV. https://www.youtube.com/watch?v=gshCsdae8Bg. Acesso em 02 de junho, às $16 \mathrm{~h}$.

ZILBERMAN, R. A literatura infantil na escola. 11 ed. Revista, atualizada e ampliada. São Paulo: Global, 2003.

Recebido em 19/06/2017.

Aprovado em 12/08/2017.

CARVALHO, H. (Con) fabulando na praça: a criação de espaços literários e lúdicos no Festival do Livro 